\title{
PRONAF PARA QUÊ E PARA QUEM? ANÁLISE CRÍTICA DOS CENÁRIOS BRASILEIRO E GOIANO
}

\author{
PRONAF WHY AND FOR WHO? CRITICAL ANALYSIS OF THE BRAZILIAN AND \\ GOIANO SCENARIOS
}

\author{
Luciana Ramos Jordão ${ }^{1}$ \\ Thiago Henrique Costa Silva ${ }^{2}$ \\ Lívia Sales Carneiro Carvalho ${ }^{3}$
}

\begin{abstract}
RESUMO
O artigo analisa a discussão do Programa Nacional de Fortalecimento da Agricultura Familiar, a partir dos sujeitos alcançados, a fim de verificar sua efetividade e atenção às diretrizes que pautaram sua criação. Objetiva fazer uma análise qualitativa com uma discussão crítica de dados secundários sobre a quantidade de contratos assinados e o volume de investimentos, bem como sua distribuição entre os estados brasileiros. Para tanto, discute-se os conceitos de agricultura familiar e campesinato bem como consequências advindas da estruturação legislativa brasileira. Assim, a partir da análise de dados da política pública do Brasil e de Goiás, levanta críticas à dificuldade de diversificação do tipo de produção bem como da concentração de acesso aos créditos por uma pequena parcela dos supostos beneficiários, gerando distorções no caráter inclusivo que o programa de governo busca promover.
\end{abstract}

PALAVRAS-CHAVE: PRONAF. Agricultura familiar. Campesinato. Desenvolvimento rural.

\section{ABSTRACT}

The article analyzes the discussion of the National Program to Strengthen Family Agriculture from the subjects reached in order to verify its effectiveness and attention to the guidelines that guided its creation. It performs through a qualitative analysis with a critical discussion of secondary data about the quantity of contracts signed and the volume of investments, as well as their distribution among the Brazilian states. It discusses the concepts of family agriculture and peasantry as well as consequences arising from the Brazilian legislative structure. Thus, from the data analysis of the public policy of Brazil and Goiás, will get criticism about the difficulty of

\footnotetext{
${ }^{1}$ Advogada. Professora de Direito Agrário e Ambiental do Centro Universitário Alves Faria (UNIALFA) e de Direito Civil na Universidade Estadual de Goiás (UEG). Doutoranda em Agronegócio pela Universidade Federal de Goiás (PPAGRO). Mestre em Direito Agrário pela Universidade Federal de Goiás (PPGDA). E-mail: Ir.jordao@me.com.

2 Perito Criminal da SPTC-GO. Professor de Direito Constitucional do Centro Universitário Alves Faria (UNIALFA) e do Centro Universitário Alfredo Nasser (UNIFAN). Doutorando em Agronegócio pela Universidade Federal de Goiás (PPAGRO). Mestre em Direito Agrário pela Universidade Federal de Goiás (PPGDA). E-mail: thiagocostasilva.jur@gmail.com.

${ }^{3}$ Advogada. Bacharel em Direito pelo Centro Universitário Alves Faria (UNIALFA). E-mail: livia.sales20@gmail.com.
} 
diversification of the production type, as well as the integration of its credits by a small portion of the alleged beneficiaries, generating distortions government program search promote.

KEYWORDS: PRONAF. Family farming. Peasantry. Rural development.

\section{INTRODUÇÃO}

O Programa Nacional de Fortalecimento da Agricultura Familiar (PRONAF) foi criado na década de 1990, com o mote de auxiliar os camponeses, que estavam fora ou tinham dificuldade de acompanhar o processo produtivo, por meio, em especial, da disponibilização de financiamento para a compra de maquinários e insumos necessários para geração de renda. Tratava-se, então, de uma política pública bastante abrangente, para diversos segmentos, que propagandeia independência financeira para quem se insere

Os vários tipos de créditos concedidos pelo programa podem ser destinados de forma individual ou coletiva, após o preenchimento de uma série de requisitos e garantias que devem ser fornecidas pelo agricultor. E, a despeito dos esforços para promover inclusão dos agricultores e da difusão do conhecimento voltado à inserção da agricultura familiar nos mercados, há muitos relatos acerca das dificuldades enfrentadas.

Quase 25 anos após a sua criação, percebe-se a necessidade de discutir os resultados obtidos pelo PRONAF considerando variáveis além da produtividade, conforme constava no Decreto n. 1.946, de 1996.

Originalmente, o PRONAF deveria se orientar pela melhoria na qualidade de vida dos agricultores por meio da promoção de desenvolvimento sustentável, com aumento de capacidade produtiva e novas oportunidades de emprego e renda. Nesse mister, além da abertura de linhas de financiamento, estavam previstas ações de incentivo à pesquisa, capacitação, disponibilização de assistência técnica e gerencial, além de outras medidas que objetivavam integrar trabalhadores rurais à elaboração das políticas públicas que se Ihes fossem destinadas (art. $2^{\circ}, \S^{2}{ }^{\circ}$, do Decreto n. 1.946, de 1996).

Apesar das intenções sociais apresentadas, a política pública partiu de pressupostos que ignoraram a construção histórica da estrutura agrária brasileira. Ao ignorar o conceito de campesinato, substituindo-o pela denominação agricultura 
familiar, o legislador visava conferir maior força jurídica à categoria à qual pretendia auxiliar, mas ao invés disso criou uma categoria fictícia distante da realidade e das peculiaridades dos supostos beneficiários.

Diante disso, constitui pretensão desse trabalho debater o PRONAF enquanto política pública, discutindo os sujeitos alcançados pelo programa, com o fim de verificar sua efetividade e atenção às diretrizes que pautaram sua criação.

Para tanto, o trabalho se realiza por meio de análise qualitativa com discussão crítica de dados secundários e se divide em outras três seções que antecedem a parte dedicada às considerações finais. A primeira delas dedica-se ao debate acerca dos conceitos de agricultura familiar e campesinato, delineando aspectos que conduziram à criação do PRONAF e as consequências advindas da ocultação da figura do camponês pelo legislador brasileiro. Em seguida, são apresentados dados que amparam a discussão a respeito das fragilidades do PRONAF como estratégia de desenvolvimento rural emancipatória.

Por fim, faz-se análise dos dados pertinentes ao estado de Goiás, representativo por se alinhar à realidade da maior parte dos estados brasileiros, além de ter grande parte de sua economia ligada às atividades agropecuárias. Evidencia-se, em seguida, uma semelhança entre a realidade brasileira e goiana, consubstanciada pela dificuldade de diversificação do tipo de produção, o que gera um processo de homogeneização do campo e atenta contra a soberania alimentar campesina, bem como pela concentração de acesso aos créditos por um pequeno grupo de agricultores e pecuaristas, o que amplia a desigualdade rural que a política pública deveria combater.

\section{FORJANDO CONCEITOS E POLÍTICAS PÚBLICAS A PARTIR DA AGRICULTURA FAMILIAR}

O modelo produtivo adotado desde a revolução verde, pautado na produtividade e, posteriormente, na exportação de commodities, marginalizou uma grande parte dos sujeitos do campo (DELGADO, 2012; OLIVEIRA, 2007). Ao passo em que o campo se "modernizava", o atraso deveria ser expurgado. O campo não era mais lugar para amadores, frase comumente utilizada entre as décadas de 1980 e 1990, refletia uma 
conjuntura sócio-política em que se ampliava a concentração de renda e de terra no campo, aumentando drasticamente as desigualdades sociais (AQUINO, SCHNEIDER, 2015).

Expulsos ou pressionados no campo, os camponeses ${ }^{4}$ foram se alojando nos bolsões de pobreza da cidade ou, ainda, ocupando a franja rural, resistindo e reinventando o seu modo de viver e de se organizar perante a sociedade. O panorama criado pelo que adiante se convencionaria denominar agronegócio estabelece um cenário de reivindicações sociais, sejam elas operadas por sindicados rurais ou ainda por movimentos sociais, que vez ou outra culminava em conflitos agrários e mortes dos envolvidos, especialmente da parte hipossuficiente no jogo de forças, o camponês ${ }^{5}$ (GEHLEN, 2004, OLIVEIRA, 2007).

Em meio às reivindicações e aos conflitos, as políticas públicas foram ganhando formas e espaço na agenda estatal, supostamente na tentativa de conciliar o conhecimento científico, o empirismo, a técnica, e, claro, no sentido de estabelecer um diálogo com o governo (SOUZA, 2003).

O fato é que quando a política pública é eficiente ameniza ou dispensa a necessidade de políticas sociais compensatórias. Nesse sentido, a década de 1990 foi marcada pela formulação de estratégias de desenvolvimento rural, com foco nos grupos vulneráveis pelo modelo produtivo implantado. Logo, teoricamente, as políticas deveriam atuar de forma específica, atendendo as necessidades de cada grupo, conseguindo aniquilar as desigualdades (GEHLEN, 2004).

Nesse sentido, Gehlen (2004) explicita que a primeira medida para o estabelecimento de uma política pública eficiente e para a promoção de um desenvolvimento local é a compreensão das particularidades do território, que se constrói a partir de inúmeras variáveis, como o modo de vida, a identidade política, a

\footnotetext{
4 "Numa perspectiva geral, o campesinato corresponde a uma forma social de produção, cujos fundamentos se encontram no caráter familiar, tanto dos objetivos da atividade produtiva - voltados para as necessidades da família - quanto do modo de organização do trabalho, que supõe a cooperação entre os seus membros. A ele corresponde, portanto, uma forma de viver e de trabalhar no campo que, mais do que uma simples forma de produzir, corresponde a um modo de vida e a uma cultura" (WANDERLEY, 2014, p. 26).

${ }^{5}$ Exemplos dessa violência e do aumento de conflitos no campo foram o massacre de Corumbiara (1995) e o de Eldorado dos Carajás (1996), que ocasionaram a morte de 11 posseiros e 19 trabalhadores, respectivamente, além de deixar feridos outras dezenas de envolvidos (NEVES, 2007).
} 
cultura, para além das condições físicas do meio. Posteriormente seria possível realizar um diagnóstico, a fim de se identificar todas as potencialidades existentes, no intuito de se formular uma proposta global, tentando antecipar o futuro que almeja e as estratégias que serão utilizadas, com essa análise inicial, ocorrendo a fusão da política pública com a social.

Apesar de existirem e resistirem, os camponeses não eram protagonistas de políticas públicas ou de ações estatais e esse cenário fez despontar a necessidade de repensar o modelo de desenvolvimento rural (NEVES, 2007). Aquino e Schneider (2015) relatam que, até o ano de 1990, não existia nem um conceito próprio de agricultura familiar, não possuindo nenhuma diferenciação dos grandes e médios produtores. Quando se fazia necessária a aquisição de algum crédito, todos tinham que disputar de igual para igual com as demais categorias, ficando evidente o resultado desastroso da não diferenciação.

Tão somente em meados de 1990, com inspiração no modelo europeu, Family Farming, o campesinato ganhou uma nomenclatura supostamente modernizadora, que incluiria os marginalizados do campo em uma categoria social e política, capaz de se integrar ao processo de desenvolvimento (WANDERLEY, 1996; CARNEIRO, 1997), em que a produção se integraria ao mercado, beneficiando, conjuntamente, os agricultores familiares, que aumentariam seus lucros, e toda a sociedade com o aumento da oferta e a melhor regulação de preços (ABRAMOVAY, 1998). Fundadas nessa perspectiva inclusiva e mercadológica, iniciou-se a elaboração de políticas diferenciadas, pensadas para atender as necessidades específicas desse grupo (AQUINO; SCHNEIDER, 2015).

Em uma fase embrionária, entre 1992 e 1994, no governo de Itamar Franco, foi criado o Programa de Valorização de Pequena Produção Rural (PROVAP). Dois anos mais tarde, em 1996, após remodelação do programa, já no governo Fernando Henrique Cardoso, criou-se o Programa de Nacional de fortalecimento da Agricultura Familiar (PRONAF), com o objetivo de fortalecimento da agricultura familiar 6 , mediante

\footnotetext{
${ }^{6}$ O termo é adotado, em conjunto com o PRONAF, pelo Decreto № 1.946/1996, mas somente em 2006, com o advento da Lei 11.326/2006, o termo agricultura familiar passa a compreender o produtor que: possua área de até 4 módulos fiscais; utilize a mão de obra da própria família nas atividades econômicas de seu estabelecimento, de maneira predominante; tenha renda familiar predominantemente oriundas das atividades vinculadas ao seu estabelecimento ou empreendimento; e que o dirija com sua família.
} 
apoio técnico e financeiro (AQUINO; SCHNEIDER, 2015). Tal formulação foi fruto de uma união de forças acadêmicas, políticas, de sindicalistas, especialmente os ligados à Confederação Nacional dos Trabalhadores na Agricultura (CONTAG), e até mesmo de organizações internacionais, como a Organização das Nações Unidas para Agricultura e Alimentação (FAO) e o Banco Internacional para Reconstrução e Desenvolvimento (BIRD) (NEVES, 2007).

Nessa perspectiva, o PRONAF teria o objetivo geral de consolidar a capacidade produtiva dos agricultores familiares, melhorando sua capacidade de investimento, para realização de seus projetos, contribuindo para a geração de emprego e renda nas áreas rurais e, consequentemente, melhorando a qualidade de vida (CAZZELLA, MATTEI, SCHNEIDER, 2004).

Contudo a nova nomenclatura e a estratégia adotada pelo governo foram vistas como problemáticas por alguns setores e pesquisadores. No âmbito do Movimento Sindical dos Trabalhadores Rurais (MSTR), por exemplo, houve uma divisão, com a criação do Movimento dos Pequenos Agricultores (MPA). Enquanto os primeiros resistiam aos programas governamentais, argumentando que seriam um instrumento de ampliação do capital, os segundos passaram a se organizar para se adequar a eles (SAUER, 2008).

Além do mais, a categoria "agricultura familiar" não conseguiria abarcar os múltiplos modos de vida campesinos (extrativistas, silvicultores, pescadores, agricultores, quilombolas, indígenas, ribeirinhos, dentre outros) (NEVES, 2007). Ou seja, em verdade, o construto jurídico não corresponderia à realidade social. 0 agrupamento em uma única categoria representou um anseio desenvolvimentista, voltado para o aumento da competitividade através do mecanismo produtivista, em que apenas aqueles que conseguissem se adequar permaneceriam (CARNEIRO, 1997; WANDERLEY, 2014).

Em outra perspectiva, estabelecer políticas públicas voltadas ao segmento agricultura familiar, ainda que com certas distorções, pode ser considerado um ponto positivo, senão pelo caráter econômico, pelo reconhecimento desses sujeitos que nem como beneficiários da lei. 
ao mesmo existiam enquanto sujeitos de direitos e políticas públicas (CARNEIRO, 1997).

Os integrantes da agricultura familiar estão intimamente ligados às questões culturais, à segurança alimentar, à natureza, à heterogeneidade de produção, fatores que colaboram para a promoção de um desenvolvimento local sustentável. Dessa forma, o surgimento de programas para auxiliar os agricultores familiares tornou-se fundamental para estabelecer a conexão entre o campo e a cidade (PAULA, KAMIMURA, SILVA, 2013).

A partir dessa perspectiva, o PRONAF buscou aumentar a possibilidade de investimento dos agricultores familiares para que pudessem concretizar seus projetos de produção, gerando renda e estabilizando socioeconomicamente os agricultores em seus pedaços de terra (FRIAS, LUNAS, QUEIROZ, 2015).

A escolha brasileira pelo programa efetivou-se por ser um modelo eficiente, em especial no cenário europeu. Todavia, é um pouco perturbador o fato de se apostar em uma política para a promoção de igualdade que acaba por segregar parte dos agricultores, reforçando a marginalização dos menos favorecidos ou que não se adequem às suas delimitações (BUSSONS, 2009).

A ampliação da desigualdade produzida pelo PRONAF pode ser vislumbrada quando se observa a quantidade e a localidade de acesso das políticas de crédito destinadas à agricultura familiar. De acordo com os dados do censo agropecuário de 2006, apenas $18 \%$ da categoria conseguia acessar créditos, seja pela grande burocracia exigida ou pela falta de informação (BARROS, 2010). Ademais, cerca de $65 \%$ do total de recurso é destinado aos agricultores da região sul do país (AQUINO, SCHENEIDER, 2011).

A questão é que nem todos os enquadrados como agricultores familiares correspondem ao modelo ideal para obter sucesso: um agricultor moderno, com acesso ao mercado e às informações necessárias para se tornar cada vez mais produtivo. Para Gemer (2002), quando se coloca essa ideia na cabeça dos pequenos agricultores brasileiros como o único caminho para a sua existência, é o mesmo que os colocar em um campo de batalha que não conseguirão vencer, pois buscarão um objetivo ilusório e impossível ou, por vezes, indesejado. 
De fato, nem todos os agricultores foram ou serão beneficiados pelo programa, já que seus objetivos se concentram em agricultores mais capitalizados, ou em agricultores que trabalham em mercados mais dinâmicos, em especial os ligados à agroindústria (FRIAS, LUNAS, QUEIROZ, 2015).

Sendo assim, fica notório que a principal política pública destinada aos agricultores familiares ainda apresenta alguns ajustes a serem feitos, como o respeito às diversidades existentes dentro da categoria (CORCIOLI, CAMARGO, 2014 p. 222), sob pena de descaracterizar - ou continuar invisibilizando - o camponês, retirando dele a sua capacidade de escolha e desconsiderando a sua relação com a natureza, uma vez que, para se encaixar na política pública, seria necessária uma espécie de robotização, em que o como, quando e o quê produzir passaria a ser determinado pelas exigências das políticas de crédito ${ }^{7}$.

\section{O PRONAF NA PRÁtICA E OS DESAFIOS ENFRENTAdOS PELOS AGRICULTORES}

Apesar de enfrentar críticas, o PRONAF é sempre apontado como um importante instrumento de desenvolvimento rural. No ano de 1996, o PRONAF foi criado com ações relativas a investimento, infraestrutura, serviços municipais, como capacitação e pesquisas. Desde sua reformulação, no ano de 1999, o programa veio ganhando notoriedade, e no ano de 2014 já foi responsável por 37\% do PIB da agropecuária e 9\% do PIB do País. Em 2006, a agricultura familiar se transformou em categoria social, aparecendo em dados censitários que permitiram identifica a dimensão desse segmento, que correspondia cerca de 4.367,902 estabelecimentos, correspondendo a $84,4 \%$ dos estabelecimentos agropecuários (CORCIOLI; CAMARGO, 2014; CASSUCE; CIRINO; JUNIOR, 2017).

A partir de sua reformulação, segundo Corcioli e Camargo (2014), os créditos concedidos pelo PRONAF destinam-se a: a) custeio, voltado a financiar as atividades

\footnotetext{
${ }^{7}$ Nesse sentido, Ribeiro e Dias (2013) apontam que a lógica da agricultura familiar visa cooptar os camponeses, integrando-os ao mercado, ampliando o modo de reprodução capitalista, desconsiderando o modo de vida camponês, utilizando-se de políticas voltadas para a comercialização de suas produções que exigem, em contrapartida, uma imposição de um modelo de trato com a terra e modo de produzir.
} 
agropecuárias e não agropecuárias, de beneficiamento ou de industrialização de produção própria ou de terceiros enquadrados no PRONAF, em outros termos, a aquisição de insumos, sementes, fertilizantes, dentre outros; b) investimento, que é o financiamento de atividades agropecuárias ou não agropecuárias para implantação ou modernização da estrutura no estabelecimento rural, ou seja, o agricultor pode adquirir bens duráveis que serão utilizados em diversos ciclos de produção; ou c) integralização de cotas-partes pelos beneficiários em cooperativas de produção, responsável pelo financiamento da capitalização das cooperativas.

Ademais, novas políticas foram sendo engendradas no âmbito do programa (AQUINO; SCHENEIDER, 2011). E, na tentativa de sanar a má distribuição dos recursos, tornando as políticas mais eficientes, foram criados grupos de $A$ a $E^{8}$ englobando diversos agricultores familiares, contudo os grupos mais fragilizados ( $A$ e $B$ ) rotineiramente acessam menores créditos do que os demais (WANDERLEY, 2014).

O poder público tentou contornar as dificuldades de promoção de igualdade pelo PRONAF com a criação de diversas categorias, mas com uma diversidade tão grande no país as divisões adotadas se mostraram insuficientes. Ainda, em relação a biodiversidade, o Brasil, que possui dimensões continentais, apresenta uma grande variação climática, do solo, da fauna e da flora, que certamente interfere nas atividades rurais. Somando-se a isso, a grande desigualdade econômica e a diversidade cultural são fatores que se apresentam como entraves para a eficiência do PRONAF nos moldes em que é proposto (CORCIOLI; CAMARGO, 2014).

No ano de 2014, o IBGE realizou uma pesquisa por amostra de domicílio, (PNAD), na forma de pesquisa suplementar, e, a partir desta, foi possível fazer uma análise a respeito da diversidade dos modos de vida de agricultores familiares no Brasil.

A proporção de atividades desempenhadas é de $63,01 \%$, em que a principal atividade é agrícola, e $36,99 \%$, em que a principal atividade é não agrícola. Partindo para análise sobre o uso de crédito, $85,54 \%$ não utilizaram crédito, 12,80\% usaram o crédito do PRONAF e apenas $1,66 \%$ usaram crédito de alguma outra forma. Dos

\footnotetext{
${ }^{8}$ Resumidamente, o grupo A é composto por agricultores assentados da reforma agrária; o grupo B corresponde a beneficiários com renda bruta familiar anual até $\mathrm{R} \$ 23.000,00$ (vinte e três mil reais); e os extintos grupos $C$, $D$ e $E$ seriam aqueles com maiores rendas brutas familiares ou com potencial para atingir tal patamar. Atualmente, para reduzir ainda mais os problemas de acesso aos créditos, criou-se linhas especiais para o grupo A e B.
} 
agricultores que usaram crédito rural, 79,50\% usaram PRONAF. E, dos que utilizaram crédito rural, apenas 15,62\% obtiveram algum tipo de assistência técnica (CASSUCE; CIRINO; JUNIOR, 2017).

Sobre o uso do crédito, nota-se que o nível de escolaridade influencia para a busca do crédito, e que ser proprietário do empreendimento aumenta em cerca de 1,8 vez a probabilidade de uso do PRONAF, assim, apesar de o crédito poder ser concedido mesmo a não proprietários (CASSUCE; CIRINO; JUNIOR, 2017).

Outra pesquisa foi realizada com amplitude nacional, contando com a colaboração de 27 universidades brasileiras, do Ministério do Desenvolvimento Agrário (MDA), com o apoio do Conselho Nacional de Desenvolvimento Científico e Tecnológico (CNPq), tendo o objetivo de auxiliar na compreensão das condições de vida dos agricultores familiares, partindo da visão deles. Foram escolhidas áreas menos favorecidas e cerca de 4.342 domicílios. Os dados revelam, em uma avaliação global, a satisfação dos agricultores por possuírem a garantia de subsistência de sua família, mas revelam que o grande problema não está da porteira para dentro, mas, sim, da porteira para fora (MEDINA; NOVAES, 2014).

No que se refere à área utilizada para a produção, 53\% dos domicílios familiares responderam positivamente, considerando boa ou ótima. Em relação à área utilizada, a resposta também foi de forma positiva, para $43 \%$ dos domicílios. Em outra vertente do estudo, quando questionados sobre a produtividade em relação à quantidade de trabalho, foi avaliada de forma mediana, com apenas $31 \%$ dos domicílios respondendo positivamente. Evidencia-se, assim, que se possuíssem mais tecnologia disponível, o quesito produtividade poderia ser melhor (MEDINA; NOVAES, 2014).

Quando indagados sobre a infraestrutura disponível na terra, o resultado foi positivo, pois a grande maioria dos agricultores familiares possuem acesso à energia elétrica, água em suas casas ou próximo de casa, geladeira, telefone, além de fogão a gás, o que caracteriza uma mínima qualidade de vida e condições para a produção. $O$ ponto mais negativo de todo o estudo foi a inserção no mercado, a forma de escoarem os produtos, a variedade da produção e, consequentemente, a variedade das fontes de renda, sendo que apenas $31 \%$ das famílias consideraram a produção variada. Em cada região, os agricultores enfrentam diferentes problemas em relação à venda da 
produção, assim, se faz necessária a atuação das políticas públicas para amparar essa questão (MEDINA; NOVAES, 2014).

Outra temática abordada, também não tão positiva, foi sobre a percepção das políticas públicas. $25 \%$ dos entrevistados consideraram ter condições de participar de programas do governo, apenas 21\% para conseguir ter acesso ao crédito, e 19\% para conseguir assistência técnica. No Centro-Oeste, a avaliação foi acima da média, sendo, respectivamente 26\%, 26\% e 31\% (MEDINA; NOVAES, 2014).

A partir da análise dos dados acima, é possível depreender que a nomenclatura agricultura familiar forjada para um grupo tão diverso e com tantas peculiaridades (NEVES, 2007) fragiliza qualquer política pública que a adote. Ademais, o pouco e desigual acesso às políticas de crédito do PRONAF ou de outros programas de governo demonstram que as estratégias de desenvolvimento rural selecionam os seus beneficiários, excluindo, ainda mais, aqueles que, dada as suas condições, precisariam efetivamente de ações governamentais.

\section{OS RUMOS DO PRONAF EM GOIÁS: DA INCLUSÃO PARA A EXCLUSÃO}

Em Goiás, conforme os dados oficiais do último PNAD, há 88.436 agricultores familiares, ocupando 3.326.630 hectares, o que se mostra bastante desigual quando comparado aos demais segmentos, que possuem, juntos, 47.247 estabelecimentos, ocupando 22.353.918 hectares (MEDINA, 2014).

A agricultura familiar no Estado possui grande representatividade na produção de alimentos, com destaque para o arroz e a mandioca, produzindo 51 mil e 46 mil toneladas, respectivamente, por ano, podendo ainda citar a produção leiteira, que já é tradicionalmente conectada a uma cadeia produtiva. Contudo, tal característica revela um problema (MEDINA, 2014).

Sobre o PRONAF, num aspecto geral, em Goiás, a maior parte do crédito financia atividades costumeiras como o milho, a soja e a bovinocultura (CARCIOLI; CAMARGO, 2014; PAULA, KAMIMIURA; SILVA, 2013). 
Seja pela falta de assistência técnica que promova a produção diversificada, seja pela exigência das linhas de crédito, os agricultores familiares goianos acabam enfrentando limitações na possibilidade de diversificação na produção, ficando mais restritos às atividades de pecuária e leiteira, tradicionais na região. Entretendo essa facilidade inicial gera prejuízos a longo prazo, já que os produtores que possuem sua produção menos diversificada auferem menores lucros do que os que conseguem uma atividade diversificada (MEDINA, 2016). Além do mais, essas limitações técnicas e financeiras, acabam limitando o poder de escolha do agricultor, desconsiderando os saberes tradicionais que envolvem a lida na terra.

Corroborando a afirmação acima, Carcioli e Camargo (2014) aduzem que a concentração de recursos do PRONAF em atividades tradicionais é explicada por três motivos. Inicialmente, as instituições financeiras que são as responsáveis por liberar o crédito para o agricultor facilitam a concessão do crédito para atividades já consolidadas na região. No caso de Goiás, a bovinocultura, em razão de os animais já existentes na propriedade servirem de garantia para o financiamento e o valor recebido poder facilmente ser investido na aquisição de novos animais, que aumentarão a produção e, consequentemente, as garantias, em um círculo seguro para o aporte financeiro.

Um segundo fator estaria relacionado à figura do assessor técnico, que teria maior facilidade de elaborar os projetos para atividades mais tradicionais, acontecendo, em alguns casos, inclusive, a prática de aproveitar planilhas já existentes, tendo apenas o trabalho de convencer o agricultor de que aquela escolha é a mais viável para seu negócio. E, por último, estaria a vontade de o agricultor que, por receio, prefere tentar ir em busca de atividades que são mais tradicionais, por maior segurança e facilidade (CORCIOLI; CAMARGO, 2014).

Comumente, o acesso às políticas públicas é apontado como elemento imprescindível para garantir o desenvolvimento no campo. Contudo, quando se trata do PRONAF, até mesmo para garantir um desenvolvimento econômico, ele recebe críticas, uma vez que o fomento da diversificação do sistema de produção é algo que tem que se tornar realidade, para o surgimento de produtos diferentes e uma maior 
competitividade, mas, ao contrário, acaba sendo rechaçado em virtude de um risco financeiro (MEDINA, 2014).

O que se desnuda com a análise dos rumos do PRONAF em Goiás é que a política pública está enquadrada dentro da perspectiva do atual modelo agrícola fundado na produtividade e na priorização da produção de commodities, em uma clara busca a maior satisfação do mercado e do setor financeiro em detrimento das necessidades alimentares da população (CAPORAL, COSTABEBER, 2003) ou ainda dos denominados agricultores familiares.

Segundo Caporal e Costabeber (2003), o correto seria um modelo que aceitasse a heterogeneidade dos agrossistemas, levando em consideração os conhecimentos locais, avanços científicos, socialização e usar as tecnologias disponíveis de forma menos agressiva ao ambiente e à saúde das pessoas.

A característica primordial da agricultura familiar é conseguir diversificar a sua produção e alcançar os mercados curtos, que são o instrumento para a aquisição dos principais alimentos que compõem a mesa do brasileiro, promovendo segurança alimentar e nutricional, além de diversificação econômica dessas famílias (GRISA, GAZOLLA, SCHNEIDER, 2010). Na contramão e em nome da lógica mercadológica de curto prazo, a política pública é direcionada a interesses que vão de encontra à segurança e soberania alimentar.

De acordo com Caporal e Costabeber (2003), a segurança alimentar envolve uma produção de alimentos com qualidade e em quantidade que proporcione o acesso da população aos alimentos produzidos. Requer uma agricultura sustentável, que se preocupa com o meio ambiente, mas, mesmo assim, consiga produzir alimentos em elevada quantidade. A visão é que a agricultura seja mais atenciosa com o meio ambiente, assegurando a conservação da base dos recursos naturais.

Mas para além da segurança alimentar, políticas públicas restritivas, afetam a soberania alimentar, que, segundo Almeida Filho e Scholz (2008), consistem no direito dos povos e das comunidades em definir a suas políticas agrícolas, de trabalho, de alimentação e de terras, respeitando a diversidade e as peculiaridades de suas realidades. 
Para além da interferência no plano decisivo dos agricultores familiares, tal qual no cenário nacional, não obstante que o crédito aumente a cada ano agrícola, o valor aplicado sempre ficou abaixo e o número de contratos realizados permanece inalterado, o que propicia a conclusão de que o número de beneficiários permanece o mesmo, aumentando apenas a concentração de recursos para uma parcela específica de camponeses (CORCIOLI, CAMARGO, 2014).

No Plano Safra de 2014/2015, por exemplo, o valor aplicado na pecuária foi $\mathrm{R} \$$ 522,5 milhões, sendo 21 mil contratos e para a agricultura o valor não chegou a $R \$ 70$ milhões, sendo quase 2 mil contratos. No Estado de Goiás, no ano de 2005 o valor foi de $\mathrm{R} \$ 173$ milhões e o número de contratos de pouco mais de 29 mil. No ano de 2014, o valor aplicado foi de $R \$ 588$ milhões e incrivelmente o número de contratos caiu para 23 mil, apontando a concentração de recursos em agricultores que já tem acesso ao programa (CORCIOLI, CAMARGO, 2014).

Portanto, analisando a amplitude da política pública no cenário goiano, fica evidente que, apesar de o PRONAF garantir a existência jurídica de um grande grupo denominado legalmente por agricultores familiares, na prática, ele cria distorções que supostamente combateria, promovendo a ampliação da desigualdade social no meio rural na medida em que concentra recurso, além de desconsiderar os modos de vida campesinos e as suas soberanias alimentares, uma vez que busca promover uma homogeneização produtiva em nome do mercado.

\section{CONSIDERAÇÕES FINAIS}

A análise crítica de uma política pública constitui importante passo no seu aprimoramento. Por certo, muitos agricultores brasileiros que tiveram acesso ao PRONAF foram bem-sucedidos em seus objetivos de melhoria existencial, mas a lógica sobre a qual foi pensada gerou distorções que precisam ser enfrentadas.

De fato, não se almeja o desfazimento dessa importante política, contudo, há que se assumir que, dentro dos extremos que compõem a categoria de agricultores familiares, existem aqueles que são apenas formalmente atendidos pela política 
pública. Nem todo agricultor familiar se enquadra na receita de produtor ou agricultor dos estados da região sul do Brasil, dignos de apresentação em programas de TV por sua modernização e produtividade, pois a esses o PRONAF se amolda perfeitamente. Do lado oposto, o que se percebe é que dificilmente haverá circunstância em que o financiamento advindo do referido programa sirva a maior parte do que se convencionou chamar de agricultores familiares brasileiros.

De outro modo não poderia ser, pois a concessão dos financiamentos depende de decisões que consideram riscos inerentes ao mercado e não ao modo de vida dos agricultores camponeses. Tal fato revela que enquanto a elaboração e aplicação das políticas públicas se mantiver alheia à construção histórica e social que permeia o campo brasileiro, o baixo índice de atendimento da população continuará sendo uma constante.

Apesar de o legislador ter colocado os camponeses em seu caldo conceitual, a política pública a eles não se destina. Por isso, de nada adianta culpar aqueles que não conseguem ou não querem acessar o crédito oriundo do PRONAF, imputando-Ihes a pecha de preguiçosos, atrasados, resistentes ou despreparados.

Assim, a principal crítica a ser tecida é a priorização da produção de commodities e a homogeneização dos gêneros financiáveis pelo PRONAF, o que contraria aspectos caracterizadores do campesinato, servindo como ferramenta de substituição dos arranjos produtivos locais e das tecnologias já adaptadas à cultura e ao uso e potencialidades da natureza onde vivem os camponeses.

A análise dos dados realizada no presente trabalho se soma à experiência que se pode ter a partir do contato com agricultores que relatam não mais buscarem linhas de financiamento por receio de se verem obrigados a empreender atividades com as quais não tem familiaridade ou que são excessivamente penosas.

São comuns, por exemplo, as queixas de beneficiários da reforma agrária do Estado de Goiás acerca das dificuldades de se trabalhar com gado leiteiro. Cansados de trabalhar para "sustentarem suas vacas", quitam como podem o financiamento e prometem a si mesmos não mais retornar ao PRONAF.

Ainda que de louvável iniciativa, a política pública destinada à agricultura familiar carece de considerar outros fatores, principalmente os relacionados aos sujeitos 
a quem se destinam e, para tanto, não há outro caminho que não passe pelo ouvir e vivenciar o campesinato e os motivos que o afastam ou impossibilitam do acesso ao programa. O PRONAF deve, assim, servir aos seus beneficiários e não servir de instrumento para enquadrá-los em uma lógica produtiva e mercadológica que não os cabem.

\section{REFERÊNCIAS}

ABRAMOVAY, Paradigmas do Capitalismo Agrário em Questão 3. ed. São Paulo: Edsusp, 1998.

ALMEIDA FILHO, Niemeyer; SCHOLZ, Vera. Soberanía alimentaria y seguridad alimentaria. Anais do XLVI Congresso da Sober, Rio Branco: 2008.

AQUINO, Joacir Rufino de; SCHNEIDER, Sergio. O Pronaf e o desenvolvimento rural brasileiro: avanços, contradições e desafios para o futuro. In: GRISA, Catia;

SCHNEIDER, Sergio (Org.). Políticas públicas de desenvolvimento rural no Brasil. Porto Alegr: UFRGS, 2015. p.53-77.

. 12 anos da política de crédito do PRONAF no Brasil (1996-2008): uma reflexão crítica. Revista de extensão e estudos rurais. v. 1, n. 2, p. 309-347, jul.-dez. 2011.

ASSIS, Renato Linhares de. Desenvolvimento rural sustentável no Brasil: Perspectivas a partir da integração de ações públicas e privadas com base na agroecologia. Revista de Economia Aplicada. Ribeirão Preto, v.10, n.1 p.75-89, mar 2006. Trimestral.

BARROS, Geraldo Sant'Ana de Camargo. Política agrícola no Brasil: subsídios e investimentos. In: GASQUES, J.G.; VIEIRA FILHO, J.E.R.; NAVARRO, Z. A agricultura brasileira: desempenho, desafios e perspectivas, IPEA, cap. 11, p. 237-258, 2010.

BUSSONS, Nicolau de Lima. Concepções da agricultura Familiar: que ações norteiam o Programa Nacional da Agricultura Familiar (PRONAF). 2009. Disponível em: <joinpp.ufma.br/jornadas/joinppIV/eixos/9_estados-e-lutas-sociais/concepções-de agricultura-familiar-que-acoes-norteiam-o-programa-nacional-de-fortalecimento-dapdf>. Acesso em: 12 dez. 2017. 
BRASIL. Banco Central do Brasil. FAQ: Programa Nacional de Fortalecimento da Agricultura Familiar (PRONAF). Brasília, 2015. Disponível em: <http://www.bcb.gov.br/? PRONAFFAQ>. Acesso em: 23 dez. 2017.

CAPORAL, Francisco Roberto; COSTABEBER, José Antônio. Segurança alimentar e agricultura Sustentável: uma perspectiva agroecológica. 2003. Disponível em: <file:///C:/Users/Samsung/Downloads/SeguranÃßa_alimentar_e_agricultura_sustent $\tilde{A}_{j \mathrm{~V}}$ el.pdf>. Acesso em: 21 dez. 2017

CARNEIRO, Maria José. Política pública e agricultura familiar: uma leitura do Pronaf. Revista Estudos, Sociedade e Agricultura, abr. 1997.

CASSUCE, Francisco Carlos da Cunha; CIRINO, Jader Fernandes; ROCHA JUNIOR, Adauto Brasilino. Determinantes do uso do crédito rural do Pronaf em 2014. Revista da Política Agrícola. Brasília, v.2, p.101-114, out. 2017.

CORCIOLI, Graciella; CAMARGO, Ricardo de Siqueira. Programa nacional de fortalecimento da agricultura familiar (PRONAF). In: MEDINA, Gabriel. Lições para assessoramento técnico. 3 ed. Goiânia: UFG, 2014. p.201-224.

DELGADO, Guilherme C. Do capital financeiro na agricultura à economia do agronegócio: mudanças cíclicas em meio século (1965 - 2012). Porto Alegre: Editora da UFRGS, 2012.

FRIAS, Ozamir Alves; LUNAS, Divina Aparecida Leonel; QUEIROZ, Gilberto José de Faria, Análise do crédito PRONAF no estado de Goiás no período de 200-2011.Revista Desenvolvimento Socioeconômico em Debate. Montes Claros-MG, v.1, n.2, p. 6-26, maio 2015.

GEHLEN, Ivaldo. Políticas Públicas e Desenvolvimento Social Rural. São Paulo em Perspectiva, São Paulo, v.18, n², p. 95-102, jun.2004.

GERMER, Claus. M. A irrelevância prática da agricultura "familiar" para o emprego agrícola. Reforma Agrária v. 31, n 1, jan/abr, p.47-62. 2002.

GRISA, Cátia; GAZOLLA, Marcio; SCHNEIDER, Sérgio. A "produção invisível" na agricultura familiar: Autoconsumo, segurança alimentar e políticas públicas de desenvolvimento rural. Agroalimentaria. Mérida- Venezuela, v.16, n.31, p.65-78, dez. 2010.

GUANZIROLI, Carlos Enrique; SABBATO, Alberto di. Existe na agricultura brasileira um setor que corresponde ao "family farming" americano? Revista de Economia e 
Sociologia Rural. Brasília, v.52, supl.1 p.S085-S104, fev.2014. Trimestral. Disponível em: <http://www.scielo.br/pdf/resr/v52s1/a05v52s1.pdf>. Acesso em 10 set.2017.

MEDINA, Gabriel. Agricultura familiar em Goiás: lições para assessoramento técnico. 3.ed. Goiânia: UFG, 2016.

MEDINA, Gabriel; NOVAES, Evandro. Percepções dos agricultores familiares brasileiros sobre suas condições de vida. Interações: Revista Internacional de Desenvolvimento Local, Campo Grande, v.15, n.2, p.385-397, dez. 2014. Trimestral.

MIRANDA, Carlos Luiz de; ADIB, Alberto Renault. Multifuncionalidade e desenvolvimento rural sustentável: Educação para o desenvolvimento humano sustentável: Multifuncionalidade e Agricultura Familiar, Rio de Janeiro: Instituto Souza Cruz, vol.09, n.1, ago. 2007.p.8-12

NEVES, Delma Pessanha. Agricultura familiar: Quantos ancoradouros! In: FERNANDES, Bernardo Mançano; MARQUES, Marta Inez Medeiros; SUZUKI, Julio Cesar (orgs.). Geografia Agrária: Teoria e Poder. - 1.ed. - São Paulo: Expressão Popular, 2007. p. 211-270.

OLIVEIRA, Ariovaldo Umbelino de. Modo capitalista de produção, agricultura e reforma agrária. São Paulo: FFLCH/Labur Edições, 2007.

PAULA, Marcia Maria de; KAMIMURA, Quésia Postigo; SILVA, José Luis Gomes da. Mercados institucionais na agricultura familiar: Dificuldades e Desafios. Revista da Política Agrícola, Brasília, v.1, n 23, p.33-43, mar. 2014. Trimestral.

RIBEIRO, Dinalva Donizete; DIAS, Mariza Souza. Políticas Públicas para a agricultura familiar: o PAA e o PNPB. Mercator, Fortaleza, v. 12, n. 27, jan. - abr. 2013, p. 81-91.

SAUER, Sérgio. Agricultura familiar versus agronegócio: a dinâmica sociopolítica do campo brasileiro. Texto para discussão. Embrapa informação tecnológica. Brasília, 2008.

SOUZA, Celina. Estado da Arte da Pesquisa em Políticas Públicas: Conceitos e Principais Tipologias. In: Encontro Anual da Associação Nacional de Pós-Graduação e Pesquisa em Ciências Sociais. 2003, Caxambu-MG. Artigo. Caxambu: ANPOCS, 2003, p.1-16.

SCHNEIDER, Sergio; MATTEI, Lauro; CAZELLA, Ademir Antônio. Histórico, caracterização e dinâmica recente do PRONAF: Programa Nacional de Fortalecimento 
da Agricultura Familiar. Políticas Públicas e participação Social no Brasil Rural, Porto Alegre, p.21-50, jan, 2004.

WANDERLEY, Maria Nazareth Baudel. O campesinato brasileiro: uma história de resistência. RESR, Piracicaba-SP, vol. 52, supl.1, p. 25-44, 2014.

Raízes históricas do campesinato brasileiro. Trabalho apresentado no XX Encontro Anual da ANPOCS. GT 17 - Processos sociais agrários. Caxambu-MG. Out. 1996. 